\title{
Morphine Promotes Rapid, Arrestin-Dependent Endocytosis of $\mu$-Opioid Receptors in Striatal Neurons
}

\author{
Helena Haberstock-Debic, Kyung-Ah Kim, Y. Joy Yu, and Mark von Zastrow \\ Departments of Psychiatry and Cellular and Molecular Pharmacology, University of California, San Francisco, San Francisco, California 94143
}

\begin{abstract}
Morphine activates $\mu$-opioid receptors (MORs) without promoting their rapid endocytosis in a number of cell types. A previous study suggested that morphine can drive rapid redistribution of MORs in the nucleus accumbens, but it was not possible in this in vivo study to identify a specific membrane trafficking pathway affected by morphine, to exclude possible indirect actions of morphine via opiateregulated neural circuitry, or to define the mechanism of this morphine-dependent regulation. In the present study, we addressed these questions using dissociated primary cultures of rat striatal neurons as a model system. Morphine promoted a rapid redistribution of both endogenous and recombinant MORs within $30 \mathrm{~min}$ after drug addition to the culture medium. This effect was mediated by rapid endocytosis and occurred in a cell-autonomous manner, as indicated by its detection in cells plated at low density and in cultures in which depolarization was blocked by tetrodotoxin. Morphine-induced endocytosis of MORs was quantitatively similar to that induced by the enkephalin analog D-Ala ${ }^{2}-\mathrm{N}$-Me-Phe ${ }^{4}-\mathrm{Glycol}^{5}$-enkephalin, and endocytosis induced by both ligands was inhibited by a dominantnegative mutant version of arrestin-3 ( $\beta$-arrestin-2). These results extend previous in vivo results and indicate that morphine is indeed capable of driving rapid endocytosis of $\mu$-opioid receptors in an important subset of opiate-responsive CNS neurons. They also suggest a cellular mechanism by which $\beta$-arrestins may modulate the physiological effects of morphine in vivo.
\end{abstract}

Key words: opiate; receptor trafficking; striatal neurons; acute morphine; endocytosis; $\beta$-arrestin-2

\section{Introduction}

Morphine mediates most of its physiological effects by activating the $\mu$-opioid receptor (MOR), a G-protein-coupled receptor (GPCR) that is also activated by natively produced opioid neuropeptides (Kieffer, 1999; Evans, 2000). A fundamental mechanism of opioid receptor regulation involves rapid endocytosis of receptors via clathrin-coated pits (Keith et al., 1996; Chu et al., 1997). Endocytosis has been proposed to contribute to both attenuated opioid signaling after acute agonist activation and the rapid recovery of opioid responsiveness after agonist removal (Qiu et al., 2003). The latter role is thought to be particularly important (Koch et al., 1998), although endocytosis can also promote receptor downregulation, leading to a prolonged reduction of cellular opioid responsiveness (Afify et al., 1998; Tsao and von Zastrow, 2000). Hence, endocytosis of opioid receptors is an important regulatory process with potentially diverse functional consequences.

Whereas various opioid peptide agonists promote rapid endocytosis of opioid receptors, morphine-activated receptors are relatively resistant to this regulatory process (Keith et al., 1996;

Received Dec. 10, 2004; revised July 1, 2005; accepted July 18, 2005.

These studies were supported by research grants from the National Institutes of Health (National Institute on Drug Abuse and National Institute of Mental Health) (M.v.Z.). H.H.-D. was supported by National Research Service Award Grant DA06003. We thank Dr. Adena Svingos for critical help and discussion in early stages of this work and Drs. Rani Dhavan, Robert Edwards, Eric Nestler, Jamil Kanaani, and Steinnun Baekkeskov for valuable advice. We thank Drs. Jeffrey Benovic, Marc Caron, and John Rubenstein for key reagents.

Correspondence should be addressed to Mark von Zastrow, Mission Bay Genentech Hall, 600 16th Street, University of California, San Francisco, San Francisco, CA 94143-2140. E-mail. zastrow@itsa.ucsf.edu.

DOI:10.1523/JNEUROSCI.5045-04.2005

Copyright $\odot 2005$ Society for Neuroscience $\quad$ 0270-6474/05/257847-11\$15.00/0
Alvarez et al., 2002; Borgland, 2001). Endocytosis of opioid receptors is regulated by phosphorylation and association with nonvisual ( $\beta$-) arrestins (Whistler and von Zastrow, 1998; Zhang et al., 1998). Morphine-activated receptors are generally phosphorylated to a smaller degree (Yu et al., 1997; Zhang et al., 1998) or with slower kinetics (Schulz et al., 2004) than receptors activated by opioid peptide agonist, contributing to distinct functional consequences (Koch et al., 2001).

Much of what is known about opioid receptor traffic has been learned using heterologous cell models. With some exceptions (Kim and von Zastrow, 2003), similar processes occur in neurons (Sternini et al., 1996; Keith et al., 1998; Whistler et al., 1999; Trafton et al., 2000; Borgland, 2001; Alvarez et al., 2002; Bushell et al., 2002; Connor et al., 2004). Studies in heterologous cells indicate that morphine-induced endocytosis of MORs can be greatly enhanced by overexpressing G-protein-coupled receptor kinases (GRKs) or arrestins (Whistler and von Zastrow, 1998; Zhang et al., 1998). However, we are not aware of previous evidence that morphine promotes rapid endocytosis of opioid receptors to a comparable degree as opioid peptide agonists in cells expressing these regulatory proteins at endogenous levels.

We observed previously that systemic morphine injection produced a rapid increase in intracellular MOR immunoreactivity visualized in nucleus accumbens (Haberstock-Debic et al., 2003). However, in this in vivo study, we were unable to elucidate any mechanisms underlying this unexpected regulatory effect of morphine, including whether this effect is mediated by regulation of MORs in endocytic or biosynthetic membrane pathways (Haberstock-Debic et al., 2003; Kim and von Zastrow, 2003) or whether this regulatory effect is a direct action of morphine or an 
indirect consequence of endogenous enkephalin release (Shiomi et al., 1981). Here we have investigated these questions using primary cultures of dissociated rat striatal neurons, a preparation that is thought to be representative of the major GABAergic medium spiny neurons present in the nucleus accumbens (Heimer et al., 1982).

\section{Materials and Methods DNA constructs}

A FLAG (DYKDDDD) epitope-tagged version of the cloned murine $\mu$ (MOR1) (Kaufman et al., 1995) opioid receptor (gift from Dr. Chris Evans, University of California, Los Angeles, Los Angeles, CA) was cloned into pCAGGS/SE vector, a chicken $\beta$-actin-promoter-driven expression vector (Niwa et al., 1991). A $\beta$-arrestin-2 (arrestin-3)-green fluorescent protein (GFP) construct (gift from Dr. Marc Caron, Duke University, Durham, NC) was excised using SacI/DraIII sites from the vector described previously (Barak et al., 1997) and cloned in pCAGGS/SE vector using a DraIIII/EcoRI linker/adapter (+ linker, GTGAACCTTAAGATGGCGAG; - linker, AATTCTCGCCATCTTAAGGTTCACGTA). C-terminal fragment of this construct (residues 319418), which has been shown previously to have potent dominantnegative activity on arrestin-promoted endocytosis (Krupnick et al., 1997), was obtained (gift from Dr. Jeffrey Benovic, Thomas Jefferson University, Philadelphia, PA), a hemagglutinin (HA) epitope tag (YPYDVPDYA) was added to the $\mathrm{N}$ terminus, and the tagged construct was cloned into the pCAGGS/SE vector. All sequences were confirmed by dideoxynucleotide sequencing (University of California, San Francisco Genetics Core Facility, San Francisco, CA).

\section{Cell cultures and transfections: primary striatal neuronal culture}

Brains were aseptically isolated from embryonic day 17-18 rat embryos taken from pregnant Sprague Dawley rats, and the striatum (caudateputamen and nucleus accumbens) was dissected out based on the criteria of Ventimiglia and Lindsay (1998). Dissected cells were dissociated in $1 \times$ trypsin/EDTA solution (Invitrogen, Gaithersburg, MD) for $20 \mathrm{~min}$ before $1 \mathrm{ml}$ of trypsin inhibitor was added for $5 \mathrm{~min}$ at room temperature before gentle mechanical trituration using a glass pipette. All washing steps, as well as the trituration of tissue, were done in DMEM plus $10 \%$ FCS (Invitrogen). Transfections were performed using either a cationic lipid transfection reagent (Effectene; Qiagen, Hilden, Germany) or electroporation (rat neuron nucleofector system; Amaxa Biosystems, Gaithersburg, MD). When cationic lipid was used for transfection, the dissociated cells were plated out on poly-D-lysine-coated glass coverslips into 24-well plates and cultured in Neurobasal medium supplemented with B27 and L-glutamate. On days 4-6 after culture was prepared, cells were transfected and maintained in culture for 12-14 d. Neurons were transfected in 24-well plates with pCAGGS/SE plasmid containing FLAGtagged $\mu$-opioid receptor or cotransfected with pCAGGS/SE containing GFP- $\beta$-arrestin- 2 or HA-tagged dominant-negative $\beta$-arrestin- 2 . When electroporation was used for transfection, neurons were transfected immediately after dissociation and plated out on poly-L-lysine-coated glass coverslips washed previously in 70\% nitric acid and rinsed over $2 \mathrm{~d}$. Poly-L-lysine was prepared in $0.1 \mathrm{M}$ sodium borate buffer, $\mathrm{pH}$ 8.5. Electroporation was conducted using $5 \times 10^{6}$ dissociated cells, $2 \mu \mathrm{g}$ of plasmid DNA, and $100 \mu \mathrm{l}$ of rat neuron nucleofector solution. After transfection, cells were kept for $10 \mathrm{~min}$ in prewarmed RPMI media to recover before they were transferred into 24-well plates and cultured in DMEM plus $10 \%$ FCS on day 1 and then in Neurobasal medium supplemented with B27 and L-glutamate starting on day 2. Immunochemical staining procedures were performed on cultures between days 7 and 10 after plating.

\section{Immunocytochemical procedures}

Staining for endogenous MORs. For immunocytochemical localization of endogenous MORs, striatal neurons grown on poly-D-lysine-coated glass coverslips were treated $30 \mathrm{~min}$ with $10 \mu \mathrm{M}$ morphine or D-Ala ${ }^{2}-\mathrm{N}-\mathrm{Me}-$ $\mathrm{Phe}^{4}$-Glycol ${ }^{5}$-enkephalin (DAMGO) or left untreated before fixation ( $4 \%$ paraformaldehyde in $\mathrm{PBS}, 4^{\circ} \mathrm{C}$ for $20 \mathrm{~min}$ ). Specimens were permeabilized and blocked using $0.3 \%$ Triton X-100 and 1\% BSA in PBS for 60 min. Staining for MOR immunoreactivity was performed using an affinity-purified rabbit polyclonal antibody raised against the $\mathrm{C}$-terminal cytoplasmic domain (amino acids 384-398) of rat MOR1 (1:500; ImmunoStar, Hudson, WI). Primary antibody incubation was performed for $36 \mathrm{~h}$ at $4^{\circ} \mathrm{C}$ in $0.3 \%$ Triton X-100 and $1 \%$ BSA in PBS. Specimens were washed over several hours with multiple changes of ice-cold Trisbuffered saline (TBS), $\mathrm{pH} 7.4$, and then incubated with goat ant-rabbit antibody conjugated with the cyanine dye Cy3 $(3 \mu \mathrm{g} / \mathrm{ml}$; Jackson ImmunoResearch, West Grove, PA) in $0.3 \%$ Triton X-100 and $0.5 \%$ BSA in PBS for $45 \mathrm{~min}$ at room temperature. Specimens were again washed extensively in TBS and mounted to glass slides (using Fluormount antifade reagent) before examination by fluorescence microscopy.

Staining protocol for antibody "feeding" experiments. To specifically visualize internalization of FLAG-MOR from the cell surface, M1 antiFLAG monoclonal ( $3.5 \mu \mathrm{g} / \mathrm{ml}$; Sigma, St. Louis, MO) was added to the culture medium of FLAG-MOR transfected striatal neurons and incubated for $30 \mathrm{~min}$ to label surface receptors. Neurons were then incubated for an additional $30 \mathrm{~min}$ in the presence of the indicated ligand. In some experiments, specimens were quickly washed three times at the end of this incubation in PBS lacking $\mathrm{Ca}^{2+}$ and $\mathrm{Mg}^{2+}$ and supplemented with 0.04\% EDTA to dissociate ("strip") the M1 anti-FLAG antibody bound to residual surface receptors remaining in the plasma membrane (thereby leaving antibody bound only to the internalized receptors). Specimens were then fixed in $4 \%$ paraformaldehyde in PBS and washed with ice-cold TBS, and endocytosed antibody was detected by incubating permeabilized cells with Cy3-conjugated goat anti-mouse antibody ( 3 $\mu \mathrm{g} / \mathrm{ml}$; Jackson ImmunoResearch) prepared in $0.1 \%$ saponin and $2 \%$ BSA dissolved in PBS. Specimens were washed extensively in TBS and mounted as described above for fluorescence microscopy. The number of neurons displaying peripheral (membrane) receptor localization or punctate, endocytosed receptor localization were counted using coded slides, and data were accumulated from 20-60 cells per animal. Results of cell counts are expressed as means \pm SD. Statistical analysis of differences between control (untreated) and experimental (drug-treated) groups was performed using Student's $t$ test.

Colocalization of FLAG-MOR with $\beta$-arrestin, endosome markers, and microtubule-associated protein 2. Dual staining for FLAG-tagged MORs and HA-tagged mutant $\beta$-arrestin-2 in the same neurons was performed by first feeding neurons with M1 anti-FLAG ( $3.5 \mu \mathrm{g} / \mathrm{ml}$; Sigma) for 30 $\mathrm{min}$, as described above, adding the indicated ligand for an additional 30 $\mathrm{min}$, and fixing with $4 \%$ paraformaldehyde dissolved in PBS. Specimens were then washed in cold TBS, permeabilized and blocked using $0.1 \%$ saponin and $2 \%$ BSA in PBS, and then incubated with rabbit anti-HA $(0.5 \mu \mathrm{g} / \mathrm{ml}$; Invitrogen $)$ prepared in the same buffer. Bound anti-HA and M1 antibodies were visualized using fluorescein isothiocyanate (FITC)conjugated goat anti-rabbit antibody $(3 \mu \mathrm{g} / \mathrm{ml}$; Jackson ImmunoResearch) and Cy3-conjugated goat anti-mouse antibody ( $3 \mu \mathrm{g} / \mathrm{ml}$; Jackson ImmunoResearch), respectively. In experiments in which dual localization of FLAG-MOR and microtubule-associated protein 2 (MAP2) was performed, specimens were fixed with $4 \%$ paraformaldehyde in PBS, washed in cold TBS, permeabilized and blocked as indicated above, and incubated with a rabbit polyclonal anti-FLAG (Sigma) and mouse monoclonal anti-MAP2 (16 $\mu \mathrm{g} / \mathrm{ml}$; Sigma) prepared in $0.1 \%$ saponin and $2 \%$ BSA in PBS. Specimens were then washed three times with ice-cold TBS and incubated with a Cy3-conjugated goat anti-rabbit antibody (Jackson ImmunoResearch) and FITC-conjugated goat anti-mouse antibody (Jackson ImmunoResearch) diluted in $0.1 \%$ saponin and $2 \%$ BSA in PBS. Stained specimens were mounted using Fluormount and examined by epifluorescence microscopy using a Nikon (Melville, NY) Diaphot microscope equipped with a $60 \times /$ numerical aperture (NA) 1.4 objective, mercury arc lamp illumination, and standard dichroic filter sets (Omega Optical, Brattleboro, VT). Images were collected using a cooled CCD camera (Princeton Instruments, Trenton, NJ) interfaced to an Apple Computers (Cupertino, CA) Macintosh computer using IPLab (Scanalytics, Fairfax, VA) software.

For simultaneous detection of FLAG-MOR and endocytosed transferrin, specimens were serum starved for $60 \mathrm{~min}$ and incubated with Alexa488-conjugated diferric transferrin $(50 \mu \mathrm{g} / \mathrm{ml}$; Molecular Probes, Eugene, OR) in serum-free medium for $30 \mathrm{~min}$. Surface FLAG-MOR was 
labeled by incubating with $1 \mu \mathrm{g} / \mathrm{ml}$ Alexa594-conjugated M1 anti-FLAG monoclonal (prepared by standard methods using Alexa-fluor 594 $N$-hydroxysuccinimide ester; Molecular Probes), cells were incubated under the indicated conditions for $30 \mathrm{~min}$ and then fixed using $4 \%$ paraformaldehyde dissolved in PBS. Dual staining for LAMP1 and FLAG-MOR was performed by surface labeling FLAG-MORs with Alexa594-conjugated M1 as above, incubating under the indicated conditions for $30 \mathrm{~min}$, and fixing using $4 \%$ paraformaldehyde dissolved in PBS. Fixed specimens were washed three times in ice-cold TBS, permeabilized and blocked using $0.1 \%$ saponin and $2 \%$ BSA in PBS, and then incubated with anti-LAMP1 monoclonal antibody $(0.2 \mu \mathrm{g} / \mathrm{ml}$; Stressgen Biotechnologies, Victoria, British Columbia, Canada) dissolved in the same buffer for $60 \mathrm{~min}$. Specimens were then washed extensively with TBS, and Alexa488-conjugated goat-anti mouse $\operatorname{IgG}_{1}(4 \mu \mathrm{g} / \mathrm{ml}$; Molecular Probes) dissolved in $0.1 \%$ saponin and 2\% BSA in PBS was applied for $30 \mathrm{~min}$ to detect LAMP1 immunoreactivity. Specimens were then mounted to glass slides and examined using a Zeiss (Oberkochen, Germany) LSM510 confocal laser microscope using a $63 \times /$ NA 1.4 objective and a pinhole diameter of 1 Airy disc. For all colocalization experiments, manufacturer-recommended settings were used, and control imaging of single-labeled specimens was performed to confirm lack of detectable bleed through between channels.

\section{Dual-color visualization and quantitative analysis of \\ MOR internalization}

Ratiometric internalization assay using differentially labeled primary antibodies. Coverslips were incubated for $30 \mathrm{~min}$ in media containing 2 $\mu \mathrm{g} / \mathrm{ml}$ Alexa594-conjugated M1 anti-FLAG antibody to label surface receptors, incubated with $10 \mu \mathrm{M}$ morphine, $10 \mu \mathrm{M}$ DAMGO, or left untreated (control) for an additional $30 \mathrm{~min}$. Alexa594-M1 bound to residual surface (not internalized) receptors was stripped by washing three times rapidly with ice-cold PBS without $\mathrm{Ca}^{2+}$ and $\mathrm{Mg}^{2+}$ and supplemented with $0.04 \%$ EDTA, thereby leaving Alexa594-M1 antibody bound only to the internalized receptors. Neurons were then fixed in $4 \%$ paraformaldehyde in PBS without permeabilization, washed in cold TBS, and incubated with $2 \mu \mathrm{g} / \mathrm{ml}$ Alexa488-conjugated M1 anti-FLAG antibody (prepared by standard methods using Alexa-fluor 488 $\mathrm{N}$-hydroxysuccinimide ester; Molecular Probes) using nonpermeabilized conditions (2\% BSA in PBS without saponin), to label only the residual surface pool of FLAG-MOR. Epifluorescence microscopy was performed using an inverted microscope fitted with Nikon PlanApo $10 \times /$ NA 0.5 or Plan $20 \times /$ NA 0.5 dry objectives for low-magnification viewing and a Nikon PlanApo $60 \times / \mathrm{NA} 1.4$ oil objective for highmagnification viewing. To quantify receptor internalization, cell bodies were selected at random using $20 \times /$ NA 0.5 dry objectives and outlined using IPLab software to calculate integrated intensity of Alexa594 and Alexa488 fluorescence signals separately. Background signals for each channel (obtained from mean determinations from control labeling of untransfected neurons) were scaled to the integrated area of each measurement and subtracted. Another control was performed in which transfected neurons were incubated in the absence of agonist (control condition) and labeled simultaneously with Alexa488-M1 and Alexa594M1, both at $2 \mu \mathrm{g} / \mathrm{ml}$, to determine the ratio between specific Alexa488 and Alexa594 signal intensities when bound in similar amount. This ratio was used to obtain normalized green and red signal intensities from background-subtracted Alexa488 and Alexa594 determinations, respectively. The percentage of internalized receptors was then estimated as follows: $\%$ internalized $=[\mathrm{red} /($ green + red $)] \times 100$. Twenty to 30 neuronal cell bodies were analyzed per animal, derived from four animals per condition, and mean and SD of the calculated ratios were determined. Statistical analysis of differences between control (untreated) and experimental (drug-treated) groups was performed using Student's $t$ test.

Ratiometric internalization assay using differentially labeled primary and secondary antibodies. To further evaluate ligand effects on FLAGMOR internalization, an additional assay was devised that does not depend on antibody stripping. First, specimens were incubated with Alexa594-conjugated M1 for 30 min to label surface FLAG-MOR and then incubated under the indicated ligand conditions for an additional
$30 \mathrm{~min}$. Cells were then fixed without permeabilization with 4\% paraformaldehyde dissolved in PBS. Specimens were washed in ice-cold TBS and incubated with Alexa488 donkey-anti mouse IgG (Molecular Probes) for 45 min under nonpermeabilized conditions (2\% BSA in PBS without saponin) to label only primary antibodies bound to FLAG-MOR present in the plasma membrane. Internalized receptors were therefore labeled only with one fluorochrome (Alexa594), and residual surface receptors were labeled with both Alexa488 and Alexa594. Imaging of cell body regions was performed, and background was subtracted as described above from Alexa488 and Alexa594 values separately to yield net green and red signals, respectively. The percentage of receptors internalized in response to the indicated agonist was then calculated from the background-subtracted Alexa488 (green) and Alexa594 (red) values according to following formula: $\%$ internalized $=[1-($ green $/$ red ratio in agonist treated $) /($ green $/$ red ratio in nontreated $)] \times 100$. In each experiment, 50 neuronal bodies were analyzed for each condition. The results shown were compiled from two experiments representing separate animals and culture preparations. Statistical analysis of differences between control (untreated) and experimental (drug-treated) groups was performed using Student's $t$ test.

\section{Immunoblotting procedures}

Rat striatal neurons were grown in six-well plates for 7-10 d before they were lysed in cold lysis buffer $(0.1 \%$ Triton X-100, $10 \mathrm{~mm}$ Tris, $150 \mathrm{~mm}$ $\mathrm{NaCl}, 1 \mathrm{mM} \mathrm{CaCl}_{2}$, and $25 \mathrm{~mm} \mathrm{KCl}$ ) containing protease inhibitors (100 $\mu \mathrm{l} / \mathrm{ml}$ leupeptin, aprotinin, pepstatin, and $1 \mathrm{~mm}$ pefabloc) for $30 \mathrm{~min}$, gently rocking at $+4^{\circ} \mathrm{C}$. Human embryonic kidney HEK293 cells were also cultured in six-well plates and lysed using the same method. Cell extracts were obtained by centrifugation of detergent lysates in a microcentrifuge (14,000 rpm for $15 \mathrm{~min})$. The supernatant from this spin was taken as clarified extract and a volume of extract corresponding to $40 \mu \mathrm{g}$ of total protein from each extract [determined the Bradford protein assay reagent marketed by Bio-Rad (Hercules, CA), with BSA as standard] was separated by SDS-PAGE. Resolved proteins were transferred to nitrocellulose membranes (Micron Separations, Minnetonka, MN). Detection of GRK2 was performed by incubating the blots with rabbit polyclonal GRK2 antibody ( $0.4 \mu \mathrm{g} / \mathrm{ml}$; Santa Cruz Biotechnology, Santa Cruz, CA) for $60 \mathrm{~min}$, washing in TBST [ $25 \mathrm{~mm}$ Tris- $\mathrm{HCl}, \mathrm{pH}$ 7.4, $137 \mathrm{~mm} \mathrm{NaCl}, 3$ $\mathrm{mm} \mathrm{KCl,} 1 \mathrm{~mm} \mathrm{CaCl}_{2}$, and $0.1 \%(\mathrm{v} / \mathrm{v})$ Tween 20], and incubating with donkey anti-rabbit antibody conjugated to horseradish peroxidase for 30 min (Amersham Biosciences, Arlington Heights, IL). Immunoreactive proteins bands were detected using Super Signal (Pierce, Rockford, IL) and Eastman Kodak (Rochester, NY) XAR film. For detection of $\beta$-arrestin, striatal neurons and HEK293 cells were cultured in six-well plate, and cell extracts were prepared as above. Total protein $(40 \mu \mathrm{g})$ from each extract was separated by SDS-PAGE and transferred to nitrocellulose membrane, and detection was performed using antiserum
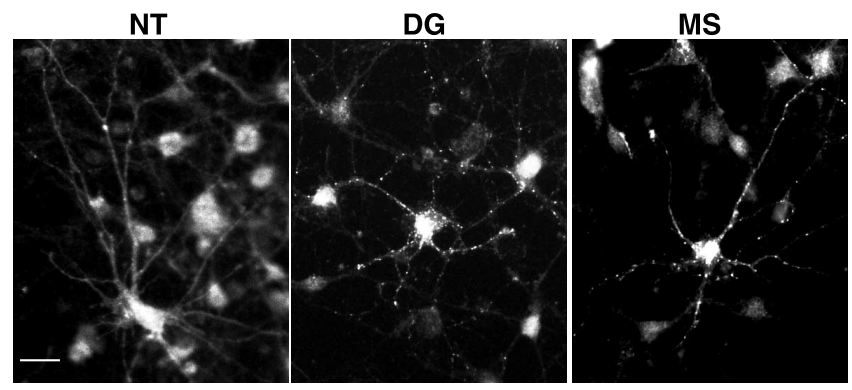

Figure 1. Both morphine and DAMGO produce rapid redistribution of endogenous MORs in cultured striatal neurons. Endogenous MOR distribution was visualized in untransfected striatal neurons by anti-MOR immunostaining under permeabilized conditions. Representative epifluorescence images show MOR distribution in the untreated condition (NT), after 30 min treatment with $10 \mu \mathrm{m}$ DAMGO (DG), or after 30 min treatment with $10 \mu \mathrm{m}$ morphine (MS). In the untreated condition, MOR were located at the plasma membrane, whereas morphine and DAMGO induced significant receptor redistribution visualized as puncta staining. Scale bar, $10 \mu \mathrm{m}$. 
raised against a sequence (residues 384-397) in $\beta$-arrestin-2 that is conserved in $\beta$-arrestin-1 (1 $\mu \mathrm{g} / \mathrm{ml}$; Affinity BioReagents, Golden, CO) for $60 \mathrm{~min}$. After washing in TBST (as above), blots were incubated with donkey anti-rabbit antibody conjugated to horseradish peroxidase for $30 \mathrm{~min}$ (Amersham Biosciences), and immunoreactive protein bands were detected using Super Signal (Pierce) and Eastman Kodak XAR film.

\section{Results}

Both morphine and DAMGO promote rapid redistribution of endogenous

MOR immunoreactivity in dissociated striatal neurons

Whereas morphine fails to produce rapid effects on MOR localization in heterologous cell models or in several neural cell types examined in situ and in culture (Keith et al., 1996; Sternini et al., 1996; Keith et al., 1998; Whistler et al., 1999; Trafton et al., 2000; Bushell et al., 2002), a pronounced change in the subcellular localization of MOR was observed in the intact nucleus accumbens within 30 min after systemic administration of morphine (Haberstock-Debic et al., 2003). To determine whether a similar effect of morphine could also be observed in cultured neurons, we examined MOR localization in primary cultures of rat striatal neurons. A large fraction of these neurons express endogenous MORs and are arguably more representative of nucleus accumbens neurons than the (primarily excitatory) hippocampal cultures used by others and us in previous studies (Whistler et al., 1999; Bushell et al., 2002). Consistent with this, a significant fraction $(\sim 60 \%)$ of neurons present in these cultures were labeled with a previously described antiserum recognizing the C-terminal cytoplasmic domain of MOR1 (Arvidsson et al., 1995). In cells cultured in the absence of opioid agonist, endogenous MOR immunoreactivity was visualized over the entire surface of the cell, consistent with localization of a major fraction of opioid receptors in the neuronal plasma membrane (Fig. 1, left). A pronounced redistribution of endogenous MORs was observed within $30 \mathrm{~min}$ after addition of DAMGO $(10 \mu \mathrm{M})$ to the culture medium, in which MOR immunoreactivity was visualized in a punctate pattern consistent with surface clustering and/or internalization of receptors (Fig. 1, middle). A closely similar punctate pattern of MOR immunoreactivity was observed in cultures incubated in the presence of morphine $(10 \mu \mathrm{M})$ for $30 \mathrm{~min}$ (Fig. 1, right). Similar results were observed in the majority $(>70 \%)$ of neurons in which endogenous MOR immunoreactivity was detected.
A
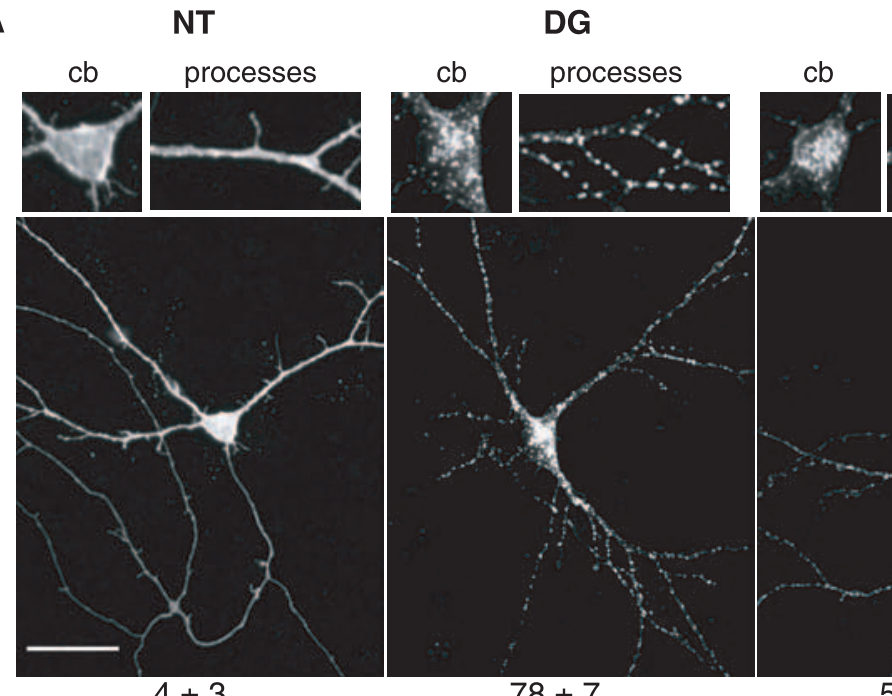

MS

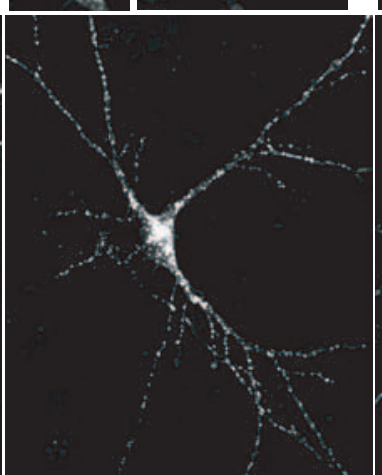

$78 \pm 7$

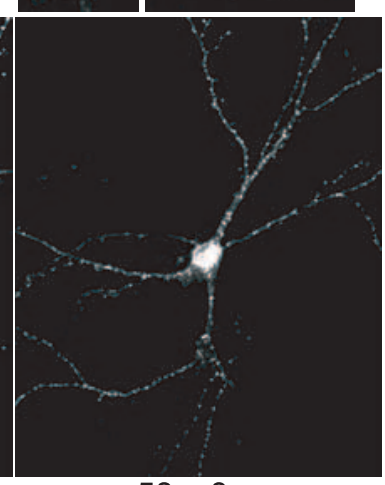

B

NT

DG

MS
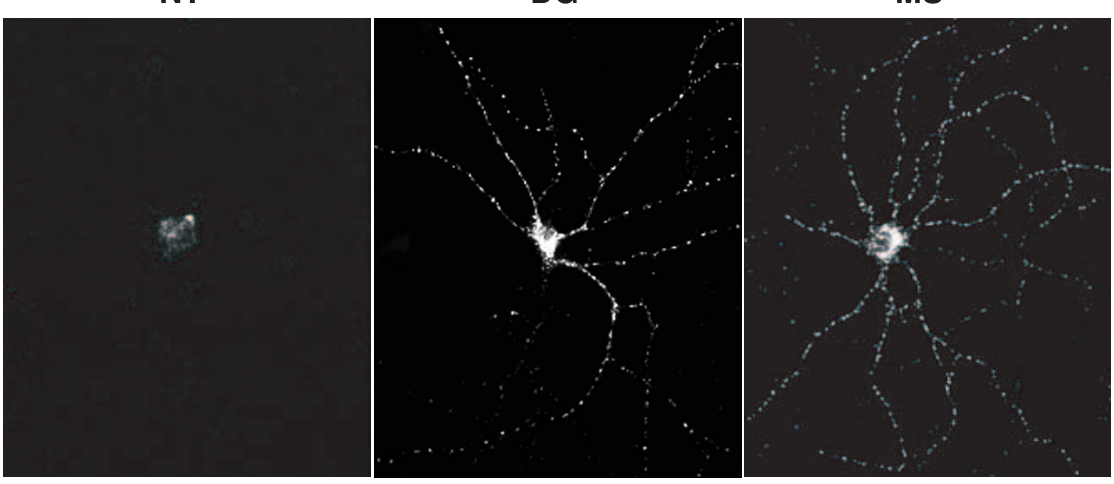

C

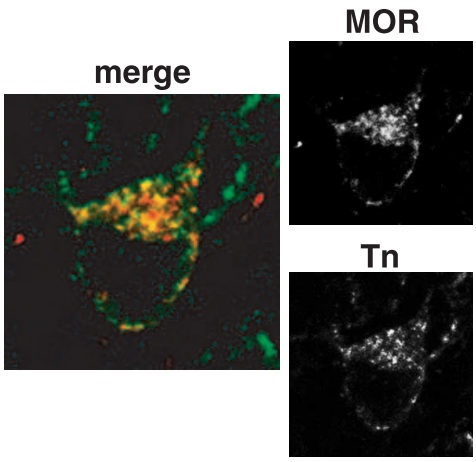

D
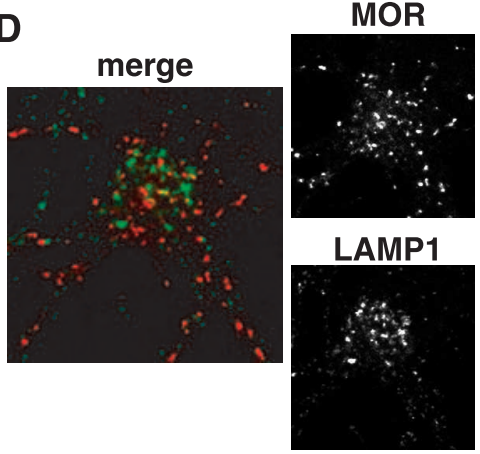

Figure 2. Both morphine and DAMGO induce rapid internalization of MOR in striatal neurons. $A$, FLAG-MOR present in the plasma membrane of transfected striatal neurons (Effectene) was specifically labeled in intact cells using M1 antibody. $\boldsymbol{A}$, Representative epifluorescence images of surface-labeled MORs obtained after 30 min incubation in the absence of agonist (NT), in the presence of $10 \mu \mathrm{M}$ DAMGO (DG), or in the presence of $10 \mu \mathrm{m}$ morphine (MS). Insets above images show typical examples of MOR localization in cell bodies $(\mathrm{cb})$ and processes under the indicated conditions. Both DAMGO and morphine produced substantial redistribution of surface-labeled MORs. $\boldsymbol{B}$, FLAG-MOR was surface labeled and treated with agonists as in $\boldsymbol{A}$. Antibody bound to receptors remaining in the plasma membrane was stripped (after the 30 min incubation period) using an EDTA wash, so that only internalized receptors were visualized. Little internalized MOR was observed in the untreated condition, whereas both DAMG0 and morphine produced significant internalization of FLAG-MOR. C, Striatal neurons expressing FLAG-MOR were briefly serum starved and then fed with Alexa488-transferrin (Tn) and Alexa594-M1 antibody to label transferrin receptor and FLAG-MOR, respectively, before treatment with morphine (30 min, $10 \mu \mathrm{m}$ ). Representative examples of merged and unmerged confocal images are shown: FLAG-MOR (red) and transferrin (green). Yellow indicates colocalization. $\boldsymbol{D}$, Striatal neurons expressing FLAG-MOR were fed with Alexa594-M1 antibody to label the surface MORs before treatment with agonist morphine ( $30 \mathrm{~min}, 10 \mu \mathrm{m}$ ). Cells were fixed and stained with mouse anti-LAMP1 antibody. An Alexa488-conjugated goat anti-mouse $\lg _{1}$ antibody was used to visualized LAMP1. Representative merged and unmerged images are shown: FLAG-MOR (red) and LAMP1 (green). Absence of yellow indicates no colocalization. Scale bar, $20 \mu \mathrm{m}$. 
A

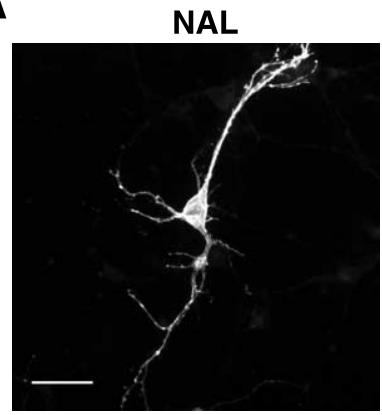

B

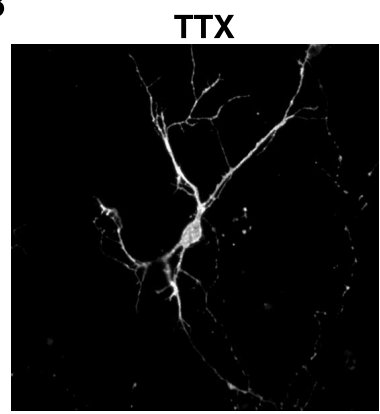

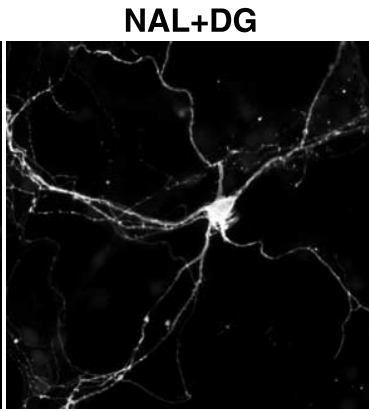

TTX+DG

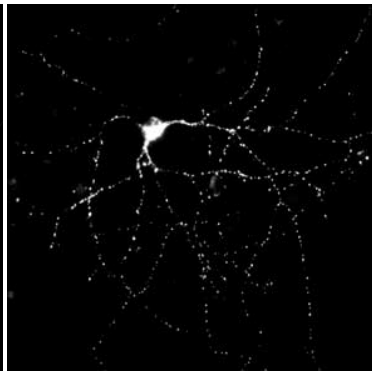

NAL+MS

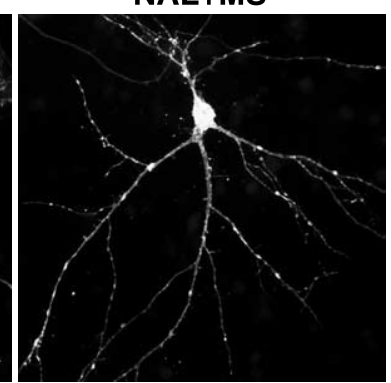

TTX+MS

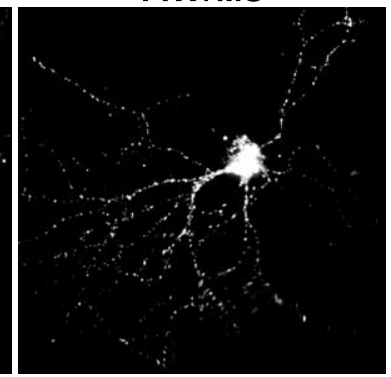

Figure 3. Morphine- and DAMGO-induced endocytosis of MORs requires receptor activation but not depolarization of neurons. $\boldsymbol{A}$, Transfected striatal neurons (Effectene) were surface labeled for FLAG-MOR, pretreated for 15 min with the opiate antagonist naloxone $(10 \mu \mathrm{M})$, and then incubated for an additional $30 \mathrm{~min}$ with naloxone only (NAL), naloxone together with $10 \mu \mathrm{m}$ DAMG0 (NAL + DG), or naloxone together with $10 \mu \mathrm{m}$ morphine (NAL + MS). Naloxone alone did not produce detectable redistribution of surface-labeled FLAG-MOR and inhibited receptor redistribution induced by both DAMGO and morphine. $\boldsymbol{B}$, Transfected striatal neurons were surface labeled for FLAG-MOR, pretreated for $15 \mathrm{~min}$ with $2 \mu \mathrm{m}$ tetrodotoxin, and then incubated for an additional 30 min with tetrodotoxin alone (TTX), tetrodotoxin together with $10 \mu \mathrm{M}$ DAMGO (TTX + DG), or tetrodotoxin together with $10 \mu \mathrm{m}$ morphine (TTX + MS). Tetrodotoxin did not produce detectable redistribution of surface-labeled MORs and did not prevent receptor redistribution induced by either DAMGO or morphine. Scale bar, $20 \mu \mathrm{m}$.

\section{Morphine-dependent redistribution of MORs is mediated by rapid endocytosis}

To specifically examine redistribution of MORs present in the plasma membrane, we used a previously described FLAG epitope-tagged version of MOR1 that allows selective labeling of recombinant receptors accessible to antibodies at the cell surface. FLAG-MOR labeled by monoclonal antibody in nonpermeabilized cells was distributed over the plasma membrane of transfected neurons (Fig. 2A, left), consistent with the appearance of endogenous immunoreactivity in permeabilized cells (Fig. 1). DAMGO induced a rapid redistribution of surface-labeled MOR from a relatively smooth distribution to a punctate localization throughout the neurons, consistent with DAMGO-induced redistribution of MOR observed previously in other neurons (Fig. $2 A$, middle and insets). Morphine also induced a rapid and pronounced redistribution of surface-labeled FLAG-MOR (Fig. $2 \mathrm{~A}$, right), consistent with the endogenous localization data (Fig. 1) but contrasting with its failure to drive detectable receptor redistribution in several other cell types. The reproducibility of these effects was confirmed by quantification of the percentage of transfected neurons in which punctate localization of FLAGMOR was observed (numbers below Fig. 2A).

Punctate redistribution of surface-labeled MORs could reflect surface clustering of opioid receptors and/or their endocytosis. To specifically determine whether morphine promotes rapid endocytosis of MORs in these neurons, residual antibody-labeled receptors remaining in the plasma membrane were selectively stripped by chelating extracellular calcium after incubation in the absence or presence of agonist. In cells incubated in the absence of opioid agonist, nearly all of the antiFLAG monoclonal was dissociated by the EDTA strip, consistent with receptors remaining predominantly in the plasma membrane in the absence of agonist activation (Fig. $2 \mathrm{~B}$, left). Within $30 \mathrm{~min}$ after addition of $10 \mu \mathrm{M}$ DAMGO to the culture medium, punctate FLAG immunoreactivity was readily apparent and was resistant to EDTA strip (Fig. $2 \mathrm{~B}$, middle). A similar pool of "protected" receptors was observed after acute morphine exposure (10 $\mu \mathrm{M}, 30 \mathrm{~min}$ ) (Fig. $2 \mathrm{~B}$, right). Internalized FLAG-MOR observed in morphineexposed neurons overlapped significantly with endocytosed transferrin, a marker of early and recycling endosomes (Maxfield and McGraw, 2004) (Fig. 2C, yellow represents colocalization). In contrast, there was no detectable colocalization with the lysosome marker LAMP1 (Fig. 2D). Similar results were observed after DAMGOinduced internalization of FLAG-MOR (data not shown), suggesting that both morphine and DAMGO induce rapid endocytosis of FLAG-MOR primarily to early and/or recycling endosomes under these conditions.

\section{Morphine-induced endocytosis of} MORs is a direct and specific consequence of opioid receptor activation in receptorexpressing neurons

The opiate antagonist naloxone $(10 \mu \mathrm{M})$ did not promote MOR endocytosis by itself and completely blocked the effects on MOR localization of both DAMGO and morphine (Fig. 3A), confirming that endocytosis induced by both agonists is specifically mediated by opioid receptor activation. A concern in the previous in vivo studies (Haberstock-Debic et al., 2003) was that morphine-induced redistribution of receptors could represent an indirect opioid effect via endogenous neuropeptide release. Indeed, a significant fraction of neurons in the nucleus accumbens contain vesicular pools of enkephalin, which strongly promotes MOR endocytosis in cultured cells (Keith et al., 1998) and is released in response to neuronal depolarization (Shiomi et al., 1981). To investigate this possibility in striatal cultures, specimens were preincubated for $15 \mathrm{~min}$ with a high concentration $(2 \mu \mathrm{M})$ of the sodium channel blocker tetrodotoxin (TTX) to prevent neuronal depolarization. The indicated opioid ligand was then added in the continuous presence of TTX for an additional 30 min. Rapid redistribution of FLAG$\mathrm{MOR}$, in response to both DAMGO and morphine, was clearly evident in the presence of TTX (Fig. 3B). Together, these results suggest that rapid endocytosis of MORs in striatal neurons can occur as a direct and specific consequence of receptor activation by morphine.

\section{Morphine and DAMGO induce rapid internalization of} MORs in all neuronal compartments except proximal axons To quantify the amount of FLAG-MOR internalization produced in striatal neurons, cultures were transfected using cationic lipid and surface-localized FLAG-MOR was specifically labeled with Alexa594-conjugated M1 monoclonal antibody, incubations 
were performed in the absence or presence of the indicated opioid for $30 \mathrm{~min}$, and the calcium dependence of M1 binding was used to selectively dissociate (strip) Alexa594-M1 conjugate from receptors remaining in the plasma membrane. Cells were then fixed, and surface-accessible receptors were labeled with Alexa488conjugated M1 monoclonal antibody. These experiments confirmed the ability of both DAMGO and morphine to induce rapid internalization of FLAG-MOR, as indicated by the pronounced increase of red (endocytosed) FLAG-MOR relative to surface (green) FLAG-MOR observed within $30 \mathrm{~min}$ after addition of either agonist to the culture medium (Fig. 4A-C). Quantification of fractional receptor internalization in multiple, randomly selected neurons was then performed using fluorescence ratio imaging (see Materials and Methods). These experiments confirmed the reproducibility of the morphine effect and indicated that morphine can drive significant rapid endocytosis of FLAG-MOR in striatal neurons (Fig. 4D).

Although pronounced morphineinduced internalization of FLAG-MOR was observed in the vast majority of transfected striatal neurons, there was potential concern about sample bias because, in our hands, the cationic lipid method results in transfection of only a small fraction $(\leq 1 \%)$ of cultured neurons. Furthermore, although we and others have extensively used the calcium dependence of the M1 antibody for surface stripping in various cell types, there was still some concern about possible confounding effects of this manipulation on receptor trafficking when applied to striatal neurons. To address these concerns, we devised a second approach to quantify FLAG-MOR internalization using electroporation, which, in our hands, transfects a relatively large proportion $(20-30 \%)$ of neurons in the culture preparation, and combined this with an immunochemical labeling method that does not require calcium depletion of the culture medium. In this method, surfaceaccessible FLAG-MOR was specifically labeled with Alexa594-M1 conjugate, and ligand incubations were performed as described above. Instead of stripping residual labeled surface receptors after ligand incubation, neurons were fixed under nonpermeabilizing conditions, and residual surface receptors (labeled already with Alexa594-M1) were selectively detected using an Alexa488-conjugated antimouse secondary antibody. Dual-color fluorescence imaging was then conducted to visualize internalized (red) and surface
A

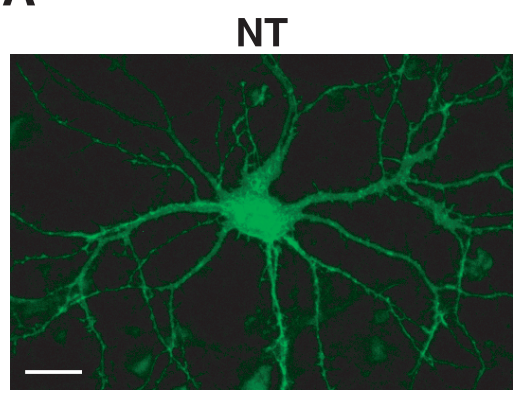

C

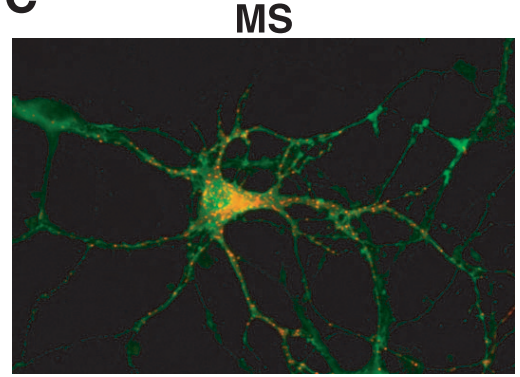

E

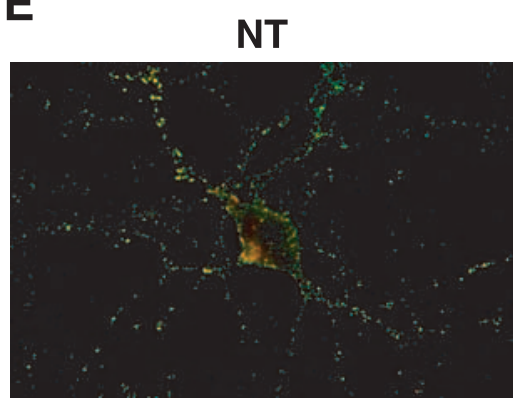

G

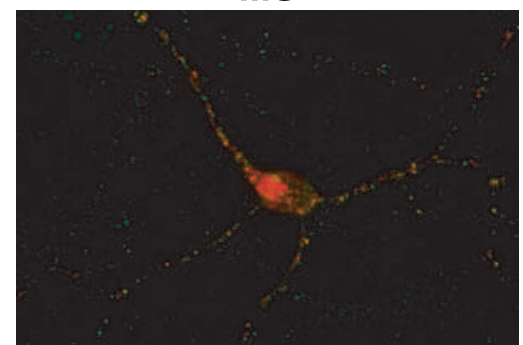

MS

Figure 4. Quantification of DAMG0 and morphine-induced internalization using dual-color ratiometric staining. A-D, FLAGMOR transfected striatal neurons (Effectene) were first surface labeled for FLAG-MOR with Alexa594-M1 antibody and then incubated for $30 \mathrm{~min}$ in the absence of agonist (NT), the presence of $10 \mu \mathrm{m} \mathrm{DAMGO} \mathrm{(DG),} \mathrm{or} \mathrm{the} \mathrm{presence} \mathrm{of} 10 \mu \mathrm{m}$ morphine (MS). Alexa594-M1 antibody was stripped from the residual surface FLAG-MOR using EDTA wash, and cells surface receptors were then labeled under nonpermeabilized conditions with Alexa488-M1. This resulted in selective labeling of internalized (red) and surface (green) FLAG-MOR. Representative images from the indicated conditions are presented in $\boldsymbol{A}-\boldsymbol{C}$, respectively. Quantitative fluorescence microscopy was used to calculate the percentage of FLAG-MOR internalization produced by DAMGO or morphine, as described in Materials and Methods $(\boldsymbol{D})$. Bars represent mean internalization determined from 20-30 cell bodies selected at random in the neuronal cultures, averaged over four independent cultures (each prepared from a separate litter). Error bars represent the SD across the determinations. $\boldsymbol{E}-\boldsymbol{H}$, FLAG-MOR-transfected striatal neurons (Nucleofector) were surface labeled for FLAG-MOR with Alexa594-M1 antibody and then incubated for 30 min without agonist (NT) or with $10 \mu \mathrm{M}$ DAMG0 or $10 \mu \mathrm{M}$ morphine. Cells were fixed and under nonpermeabilized conditions, and then residual surface receptors were labeled with Alexa488 donkey-anti mouse secondary antibody. Representative images are presented in $\boldsymbol{E}-\boldsymbol{G}$. $\boldsymbol{H}$, Quantitative fluorescence microscopy was used to calculate percentage of FLAG-MOR internalization as described in Materials and Methods. Bars represent mean internalization determined from 50 cell bodies, averaged over two independent cultures prepared from different litters. Error bars represent the SD across individual determinations. Scale bar, $5 \mu \mathrm{m}$. 
A

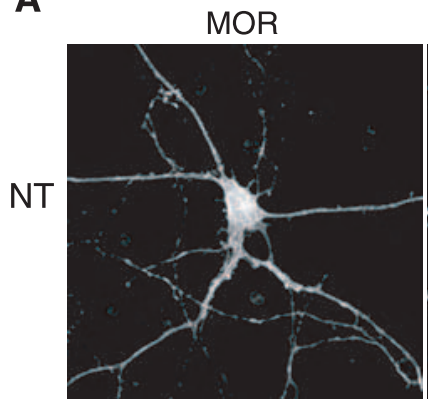

B

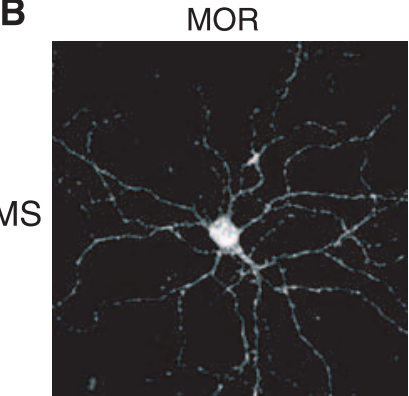

details
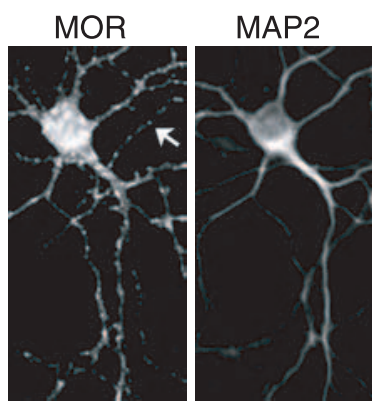

Figure 5. Morphine-induced internalization of MOR is observed both in the somatodendritic compartment and axon. FLAGMOR transfected striatal neurons (Effectene) were fixed, permeabilized, and double stained with anti-FLAG rabbit polyclonal antibody to label receptors and an anti-MAP2 mouse monoclonal antibody to mark the somatodendritic compartment. A Cy3conjugated goat anti-rabbit antibody was used to visualized MOR and FITC goat anti-mouse antibody to visualized MAP2. $\boldsymbol{A}_{\boldsymbol{i}}$ Representative images from neurons incubated in the absence of agonist (NT). FLAG-MOR was observed in a smooth distribution consistent with plasma membrane localization in both axonal (MAP2 negative) and somatodentritic (MAP2 positive) compartments. $\boldsymbol{B}$, Representative images from neurons incubated for $30 \mathrm{~min}$ in the presence of $10 \mu \mathrm{m}$ morphine (MS) before fixation. FLAG-MOR was observed in a punctate pattern consistent with internalized receptors in both MAP2-positive and -negative compartments. The detail shows increased magnification emphasizing punctate FLAG-MOR in a representative axon (arrow). Scale bar, $20 \mu \mathrm{m}$.

(red plus green) FLAG-MOR. Representative images of control (NT), morphine (MS), and DAMGO (DG) treated conditions are shown (Fig. 4E-G). Quantification of these data by ratiometric analysis (see Materials and Methods) confirmed the ability of morphine to induce pronounced rapid internalization of FLAGMOR, although in these experiments morphine did so to a somewhat smaller degree than DAMGO (Fig. $4 H$ ).

In the previous in vivo study (Haberstock-Debic et al., 2003), morphine was observed to induce a rapid redistribution of MORs selectively in dendrites relative to the cell body and axon. However, in the cultured striatal neurons, fluorescence ratio imaging suggested that morphine produced significant internalization of FLAG-MOR in cell bodies as well as in multiple processes extending from the cell body (Fig. $4 B, C$ ). To investigate this observation further, dual-label studies were performed using MAP2 as a somatodendritic marker (Fig. 5). As expected, FLAG-MOR was localized in a relatively smooth distribution over the entire surface of neurons incubated in the absence of opioid agonist (Fig.
$5 A)$. After exposure to $10 \mu \mathrm{M}$ morphine for $30 \mathrm{~min}, \mathrm{FLAG}-\mathrm{MOR}$ was localized in a punctate pattern indicative of endocytosed receptors in MAP2-positive dendrites and the cell body (Fig. 5B). We also observed significant morphine-induced redistribution of FLAG-MOR in axons defined by lack of MAP2 immunoreactivity (Fig. 5B, arrow indicates a representative axon).

In neurons cultured at sufficiently low density, the axon was unambiguously identified by morphological criteria (and confirmed by lack of MAP2 costaining; data not shown). In these neurons, fluorescence ratio imaging confirmed that morphine produced a rapid accumulation of internalized FLAG-MOR in axons (Fig. $6 A$, arrow indicates axon of a representative neuron). However, internalized FLAG-MOR (Fig. 6A, left) was visualized preferentially in distal portions $(\mathrm{d})$ of the axon but not in the proximal segment $(\mathrm{p})$, although surface FLAG-MOR (Fig. 6A, middle) was readily detected in the plasma membrane of the proximal axon. The selective internalization of FLAG-MOR in distal but not proximal axons contrasted with the visualization of internalized receptors throughout distal and proximal dendrites in the same neurons, as emphasized in the same neuron in the merged color image (Fig. 6A, right).

To quantify these observations and to compare the localization of internalized MORs produced by morphine relative to DAMGO, punctate structures containing endocytosed FLAG-MOR were counted in the axon and dendrites of multiple striatal neurons selected at random in the culture preparation. This analysis confirmed that little internalized FLAG-MOR was present in the proximal portion (defined as $0-15$ $\mu \mathrm{m}$ from cell body) of the axon in morphine-treated cells, whereas internalized FLAG-MOR puncta were plentiful in proximal dendrites (Fig. $6 B$, bars 1,2 ). In contrast, internalized FLAG-MOR puncta were plentiful in more distal portions (defined as $15-50 \mu \mathrm{m}$ from the cell body) of both the axon and dendrites of the same neurons (bars 5 and 6). The same effect was observed with DAMGO (Fig. $6 \mathrm{~B}$, bars 3,4 and 7,8$)$. Together, these results indicate that morphine can induce rapid endocytosis of MOR in all neuronal compartments, in contrast to the highly selective effect of morphine on dendritic MOR suggested in studies of receptor localization in the intact nucleus accumbens. These results also suggest that MOR present in the proximal segment of the axon is resistant to endocytosis after activation by either agonist.

\section{Morphine-induced internalization of MOR, like internalization induced by DAMGO, is mediated by a $\boldsymbol{\beta}$-arrestin-dependent mechanism}

Rapid endocytosis of opioid receptors induced by opioid peptides is mediated by a highly conserved mechanism, in which 
A
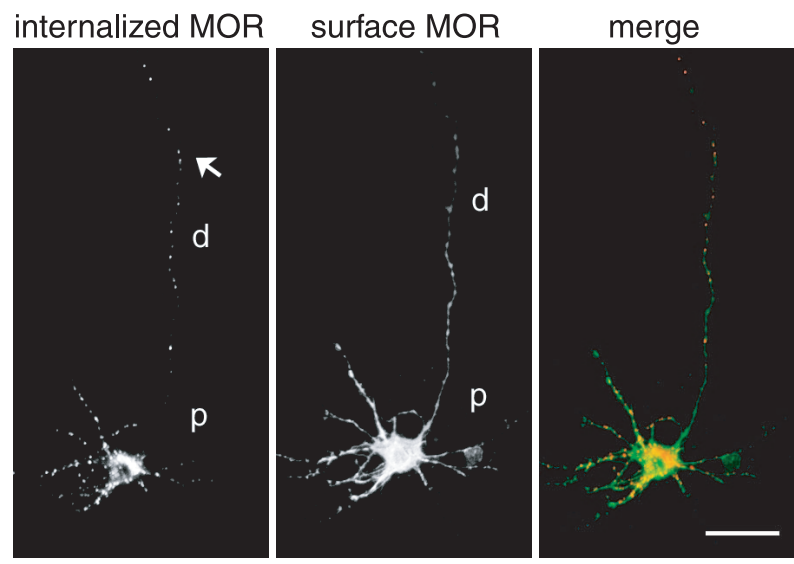

B

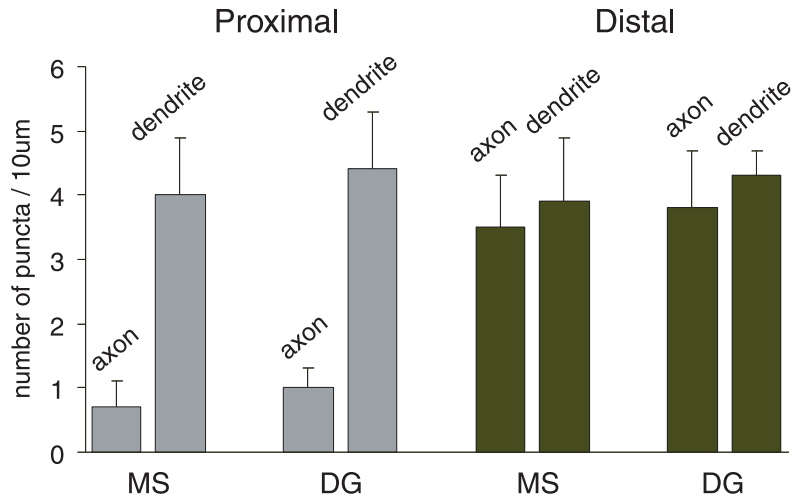

Figure 6. Reduced MOR internalization in the proximal axon. Transfected striatal neurons (Effectene) were labeled as in Figure 4 to detect internalized FLAG-MOR (Alexa594-M1) and surface FLAG-MOR (Alexa488-M1) after incubation of neurons for 30 min with $10 \mu \mathrm{m}$ morphine (MS) or $10 \mu \mathrm{M}$ DAMGO (DG). $\boldsymbol{A}$, Immunofluorescence images of a representative morphinetreated neuron (arrow indicates axon). Internalized MOR was found in the distal (d) but not proximal (p) part of the axon (left image). Surface MOR was observed in all compartments, including the proximal (p) and distal (d) axon (middle image). Scale bar, $10 \mu \mathrm{m}$. B, Quantification of density of internalized puncta in proximal and distal parts of axon and dendrites after MS and DAMG0 treatment. The proximal portion was defined as $0-15 \mu \mathrm{m}$ from cell body and the distal portion as $15-50 \mu \mathrm{m}$ from the cell body. Measurements were done on 20 cells per culture preparation, and three culture preparations (representing 3 separate litters) were analyzed per condition. Bars represent mean number of puncta per $10 \mu \mathrm{m}$, and error bars represent SD.

nonvisual (or $\beta^{-}$) arrestins play a key role by linking activated receptors to clathrin-coated pits (Whistler et al., 1998; Zhang et al., 1998). To determine whether this mechanism functions in striatal neurons and is relevant to morphine-induced endocytosis observed in these cells, the ability of a dominant-negative mutant version of arrestin-3 ( $\beta$-arrestin-2) to inhibit FLAG-MOR endocytosis was investigated. This mutant arrestin construct has been shown previously to disrupt arrestin-mediated endocytosis of various GPCRs (Krupnick et al., 1997). As expected, overexpression of HA-tagged mutant $\beta$-arrestin-2 strongly inhibited DAMGO-induced endocytosis of FLAG-MOR in striatal neurons. This was indicated by the failure of surface-labeled FLAGMOR to undergo detectable DAMGO-induced redistribution in either the cell body $(\mathrm{cb})$ or processes $(\mathrm{p})$ of striatal neurons expressing the mutant arrestin construct (Fig. 7A). In contrast, DAMGO-induced endocytosis of FLAG-MOR was readily detected in adjacent neurons not expressing mutant arrestin (Fig. 7B). However, overexpressing a GFP-tagged wild-type $\beta$-arrestin-2 at similar levels (confirmed by $\beta$-arrestin immuno- blot; data not shown) did not detectably inhibit DAMGOinduced endocytosis of FLAG-MOR, supporting the biochemical specificity of the dominant-negative effect on DAMGO-induced endocytosis of FLAG-MOR (Fig. 7C).

Identical results were obtained when the effect of mutant arrestin expression on FLAG-MOR endocytosis induced by morphine was examined. Overexpression of dominant-negative mutant $\beta$-arrestin-2 strongly inhibited morphine-induced redistribution of surface-labeled FLAG-MOR in both the cell body and neuronal processes (Fig. 7D), whereas morphineinduced endocytosis was readily apparent in neurons not expressing mutant arrestin (Fig. 7E). Endocytosis was also observed in processes extending from nontransfected neurons that were in close apposition to those extending from transfected neurons (Fig. 7D, arrow). Furthermore, overexpression of wild-type $\beta$-arrestin-2 did not prevent morphine-induced endocytosis of MOR (Fig. 7F). The inhibitory effect of dominant-negative $\beta$-arrestin mutant on ligand-induced endocytosis was significant and observed in all neurons coexpressing FLAG-MOR and dominant-negative $\beta$-arrestin ( $\sim 40 \%$ of neurons expressing FLAG-MOR also expressed dominant-negative $\beta$-arrestin). These results further confirm the importance of arrestins in promoting rapid endocytosis of MOR in response to opioid peptides, and they indicate that the same regulatory mechanism mediates morphine-induced endocytosis in striatal neurons.

The ability of morphine to promote rapid arrestin-dependent endocytosis of MORs in striatal neurons was surprising because morphine does not strongly promote this process in various other cell types, including non-neural HEK293 cells in which opioid effects on MOR trafficking have been studied in some detail. In this cell type, it is possible to greatly enhance morphineinduced endocytosis by overexpressing either $\beta$-arrestins or GRK2 (Whistler et al., 1998; Zhang et al., 1998). It has also been suggested that differences in cellular concentrations of these regulatory proteins may dictate the regulatory effects of opioid drugs in vivo (Bohn et al., 2004). Thus, we considered the possibility that cell type-specific differences in arrestin and/or GRK expression may play a role. To begin to investigate this possibility, we used immunoblotting to compare relative levels of $\beta$-arrestins in extracts prepared from striatal neurons and HEK293 cells. Immunoblotting for $\beta$-arrestins was performed using an antiserum raised against a sequence (residues 384-397) in $\beta$-arrestin-2 (arrestin-3) that is conserved in $\beta$-arrestin-1 (arrestin-2). When equal amounts of cellular extract were loaded and comparatively blotted, total $\beta$-arrestin immunoreactivity detected in striatal neurons did not exceed, and in fact was slightly less than, $\beta$-arrestin immunoreactivity detected in HEK293 cells (Fig. 7G). However, differences were observed in electrophoretic mobility of the major $\beta$-arrestin species detected. The major immunoreactive band in HEK293 cells resolved at an apparent molecular mass of $\sim 50 \mathrm{kDa}$, consistent with the electrophoretic mobility of $\beta$-arrestin-1 (arrestin-2) (Attramadal et al., 1992). The major immunoreactive band detected in striatal lysates had a slightly increased electrophoretic mobility. With the available reagents, we were unable to determine whether this species represents $\beta$-arrestin-2 (arrestin-3) or phosphorylated $\beta$-arrestin-1 (arrestin-2), both of which resolve at a slightly smaller apparent molecular mass than (unphosphorylated) $\beta$-arrestin-1 (Attramadal et al., 1992; Lin et al., 1997). To investigate relative GRK levels, we focused on GRK2, which is relatively abundant in both striatum (Erdtmann-Vourliotis et al., 2001) and HEK293 cells (Menard et al., 1997). Immunoblotting using an antiserum raised against a conserved portion of GRK2 (residues 468-689) de- 


\section{Cell expressing only FMOR}

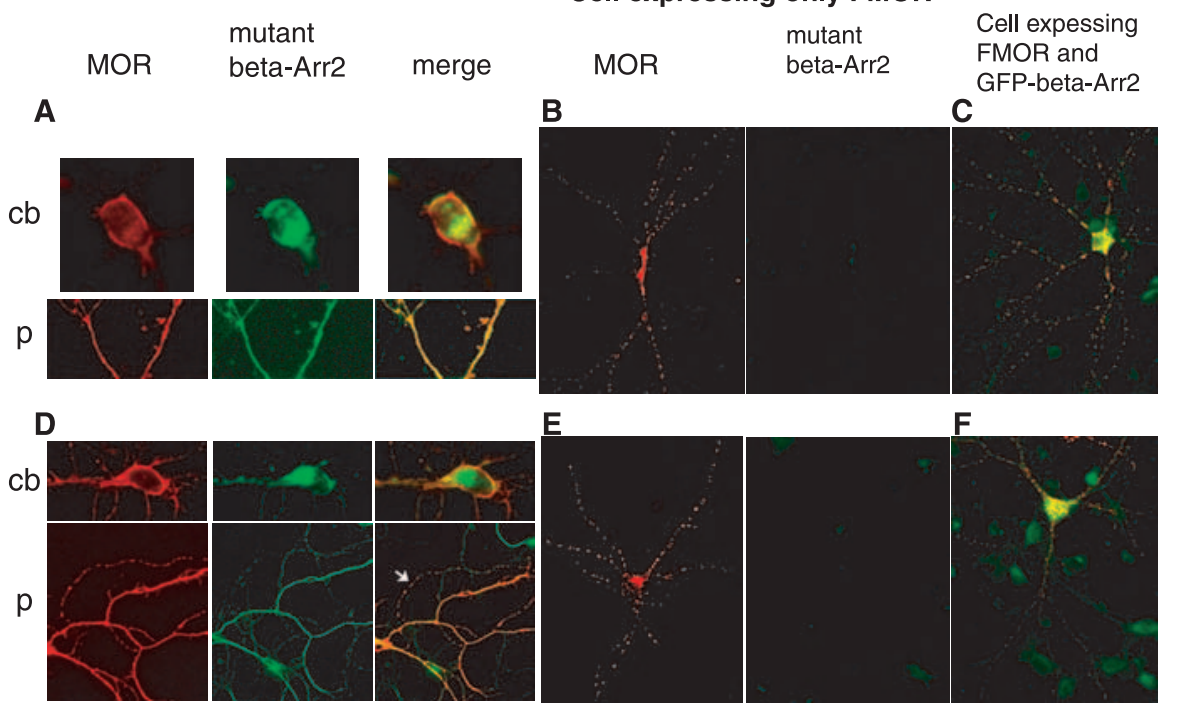

G

Arrestin

H

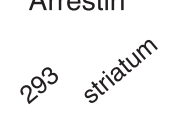

$49 \mathrm{kDa}$

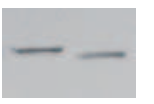

$64 \mathrm{kDa}$

Figure 7. MOR internalization induced by both morphine and DAMGO is $\beta$-arrestin dependent. Striatal neurons were cotransfected (Effectene) with FLAG-MOR (FMOR) and HA-tagged mutant $\beta$-arrestin-2. FLAG-MOR was surface labeled with M1 antiFLAG antibody, and neurons were treated with $10 \mu \mathrm{M}$ DAMGO (DG) or $10 \mu \mathrm{m}$ morphine (MS) for $30 \mathrm{~min}$. Neurons were then stained in permeabilized condition with an anti-HA antibody, and bound $\mathrm{M} 1$ and $\mathrm{HA}$ antibodies were visualized using Cy3 goat anti-mouse antibody and FITC goat anti-rabbit antibody. $A$ and $D$ show a representative neuron treated with DAMGO or morphine, respectively. Immunofluorescent images show FLAG-MOR (red) and mutant $\beta$-arrestin-2 (green) localization in cell body (cb) and processes (p) in DAMGO $(\boldsymbol{A})$ or morphine (D) -treated conditions. Note that, in cells expressing FLAG-MOR (red) and the HA-tagged dominant-negative $\beta$-arrestin-2 (green) mutant, morphine- or DAMG0-induced internalization was blocked because the majority of FLAG-MOR is localized to the plasma membrane. An arrow (D) shows a process in which MS-induced MOR redistribution and mutant arrestin was not expressed. $\boldsymbol{B}, \boldsymbol{E}$, Representative immunofluorescent images show distribution of FLAG-MOR in cells not expressing the dominant-negative $\beta$-arrestin-2 mutant after DAMGO $(\boldsymbol{B})$ or morphine $(\boldsymbol{E})$ treatment for $30 \mathrm{~min}$. Note that DAMGO or morphine induced MOR redistribution shown as puncta staining that is consistent with internalization. $C, F$, Images represent distribution of FLAG-MOR and wild-type GFP- $\beta$-arrestin-2 in DAMGO $(\boldsymbol{C})$ or morphine $(\boldsymbol{F})$-treated neurons. Note that overexpression of wild-type GFP- $\beta$-arrestin-2 did not influence DAMGO- or morphine-induced internalization. $\mathbf{G}$, A representative immunoblot of equal amounts ( $40 \mu \mathrm{g}$ of cell protein) from HEK293 or striatal neuron cultures probed with the $\beta$-arrestin-1/2 antibody. $\boldsymbol{H}$, A representative immunoblot from culture extracts probed with the GRK2 antibody.

tected a single species with indistinguishable electrophoretic mobility in both extracts. Comparative immunoblotting indicated that GRK2 levels detected in striatum were moderately elevated relative to those detected in HEK293 cells (Fig. 7H). This increase was highly reproducible across multiple culture preparations $(n=4)$ and was confirmed using a different GRK2 antibody (data not shown).

\section{Discussion}

The present results demonstrate that morphine promotes rapid redistribution of both endogenously expressed and recombinant MOR1 in striatal neurons and that this process is mediated by rapid endocytosis of receptors. Using dissociated cell culture and tetrodotoxin to block depolarization, we were able to unambiguously establish that morphine-induced endocytosis is a primary (cell-autonomous) effect of morphine on target neurons rather than a secondary effect of neural circuitry that could potentially mediate morphine-dependent endocytosis via release of endogenous opioid peptides in the intact CNS (Haberstock-Debic et al.,
2003). Furthermore, we were able to demonstrate that both morphine- and DAMGO-induced endocytosis of MOR require $\beta$-arrestins. This observation suggests a fundamental similarity between the regulatory effects of morphine and opioid peptides in a specific population of physiologically relevant CNS neurons.

Our results argue strongly that morphine-activated opioid receptors can be regulated by the GRK/arrestin system in a subset of neurons relevant to opiate responses in vivo. This contrasts with the greatly diminished effect of morphine on this regulatory process in heterologous cell models and in several other relevant neuronal populations, including neurons in cortex, gut, and spinal cord (Sternini et al., 1996; Keith et al., 1998; Trafton et al., 2000). These observations may be useful for understanding the effects $\beta$-arrestin and GRK mutations on morphine actions in intact animals (Bohn et al., 2000; Terman et al., 2004), which have so far been difficult to reconcile with the available cell biological data.

An important question for future study is why morphine promotes rapid endocytosis of MORs in striatal neurons to a greater degree than in other cell types. A reasonable possibility, supported by studies of MOR endocytosis in non-neural cell models, is that relevant GRKs and/or $\beta$-arrestins are expressed at particularly high levels in striatal neurons. Based on comparative immunoblot analysis, we think that increased expression of total $\beta$-arrestins is an unlikely explanation, because total $\beta$-arrestin immunoreactivity was actually slightly higher in HEK293 cells than in cultured striatal neurons. However, the different electrophoretic mobilities observed suggested that there may be qualitative differences in major arrestin species expressed in striatal neurons. One possibility is that the major arrestin expressed in striatal neurons is $\beta$-arrestin-2 (arrestin 3), which has slightly higher electrophoretic mobility than $\beta$-arrestin-1 (Attramadal et al., 1992). An alternative possibility is that this species represents a modified form of $\beta$-arrestin-1, such as the phosphorylated $\beta$-arrestin-1 species reported previously to have increased electrophoretic mobility (Lin et al., 1997). With presently available reagents, we were unable to determine whether the observed results reflect preferential expression of $\beta$-arrestin-2 (arrestin-3) in striatal neurons or a difference in posttranslational modification. We presently favor the latter hypothesis, because $\beta$-arrestin- 2 appears to be the major arrestin isoform expressed in several brain regions, including striatum (Gurevich et al., 2002). Either hypothesis could be functionally significant, because distinct $\beta$-arrestin isoforms have been shown to differ in their ability to promote GPCR endocytosis in heterologous cell models (Santini et al., 2000), and modification of $\beta$-arrestin-1, by both phosphorylation (Lin et al., 1997) and ubiquitination (Shenoy et al., 2001), 
affects its endocytic activity. Another possibility is that cell typespecific differences in GRK abundance could play a role in distinguishing MOR regulation in striatal neurons. The GRK isoform that is most effective in mediating morphine-induced desensitization of MOR in vitro, GRK3 (Kovoor et al., 1998), is not expressed at detectable levels in striatum (Erdtmann-Vourliotis et al., 2001). However, GRK2 is quite abundant in striatum and is capable of promoting morphine-induced desensitization and endocytosis of MORs when overexpressed in HEK293 cells (Zhang et al., 1998). Our immunoblot data indicates that GRK2 is indeed expressed in striatal neurons at higher levels than in HEK293 cells. A potential concern is that GRK2 appears to be expressed at even higher levels in some other brain regions, such as cortex (Erdtmann-Vourliotis et al., 2001), in which morphine has not been observed previously to promote rapid endocytosis of MORs (Keith et al. 1998). Furthermore, our efforts thus far to knock down GRK2 expression in striatal neurons have not revealed a selective effect on morphine-induced endocytosis of MORs (data not shown). Thus, additional study will be required to define the possible importance of quantitative or qualitative differences in GRK and/or arrestin expression in determining cell type-specific differences in morphine-induced internalization of MORs. It is also conceivable that there are additional protein(s) controlling ligand-specific endocytosis of MORs in neurons, which have not yet been anticipated from studies of non-neural cell models.

Another interesting question for future study is why morphine induces redistribution of MORs selectively in dendrites in the intact nucleus accumbens but appears to do so in all membrane domains (except proximal axons) in cultured striatal neurons. It is possible that the GRK/arrestin regulatory machinery is organized into submembrane domains in the intact tissue and that this organization is disrupted in dissociated cell culture. It is also conceivable that there are additional features of neuronal organization (perhaps involving receptor regulatory proteins in addition to GRKs and arrestins) that contribute to the specificity of receptor regulation occurring in vivo. Thus, defining the relative importance of GRK expression patterns in CNS neurons, and identifying possible additional protein(s) that regulate opioid receptor endocytosis in specific neurons or neuronal membrane subdomains, is an important direction for additional examinations. Although the present results focus exclusively on acute regulatory effects and suggest that acutely internalized receptors are localized to early and/or recycling endosomes, it will be interesting in future studies to extend the analysis to more prolonged actions of opioids. For example, chronic morphine, but not etorphine, increases total $\mu$-opioid receptor binding in several regions of rat brain, including the striatum (Tao et al., 1987; Brady et al., 1989; Reddy et al., 1994). This suggests that additional mechanisms of regulation (such as control of receptor biosynthesis) may play a major role in chronic settings and emphasizes the potential importance of future studies to determine how MORs are sorted at later times after endocytosis.

The present results provide a fundamental advance in our understanding of opiate drug action by establishing that morphine can promote rapid endocytosis of MORs and do so by a similar mechanism as opioid peptides and in a physiologically relevant population of CNS neurons. These results revise our previous view of morphine simply as a "non-internalizing" ligand in the nervous system and suggest that cell type-specific differences in receptor regulation may contribute to determining the physiological actions of opiate drugs in vivo.

\section{References}

Afify EA, Law PY, Riedl M, Elde R, Loh HH (1998) Role of carboxyl terminus of mu- and delta-opioid receptor in agonist-induced downregulation. Brain Res Mol Brain Res 54:24-34.

Alvarez VA, Arttamangkul S, Dang V, Salem A, Whistler JL, von Zastrow M, Grandy DK, Williams JT (2002) $\mu$-Opioid receptors: ligand-dependent activation of potassium conductance, desensitization, and internalization. J Neurosci 22:5769-5776.

Arvidsson U, Riedl M, Chakrabarti S, Lee JH, Nakano AH, Dado RJ, Loh HH, Law PY, Wessendorf MW, Elde R (1995) Distribution and targeting of a $\mu$-opioid receptor (MOR1) in brain and spinal cord. J Neurosci 15:3328-3341.

Attramadal H, Arriza JL, Aoki C, Dawson TM, Codina J, Kwatra MM, Snyder SH, Caron MG, Lefkowitz RJ (1992) Beta-arrestin2, a novel member of the arrestin/beta-arrestin gene family. J Biol Chem 267:17882-17890.

Barak LS, Ferguson SS, Zhang J, Caron MG (1997) A beta-arrestin/green fluorescent protein biosensor for detecting $\mathrm{G}$ protein-coupled receptor activation. J Biol Chem 272:27497-27500.

Bohn LM, Gainetdinov RR, Lin F-T, Lefkowitz RJ, Caron MG (2000) $\mu$-Opioid receptor desensitization by $\beta$-arrestin-2 determines morphine tolerance but not dependence. Nature 408:720-723.

Bohn LM, Dykstra LA, Lefkowitz RJ, Caron MG, Barak LS (2004) Relative opioid efficacy is determined by the complements of the G proteincoupled receptor desensitization machinery. Mol Pharmacol 66:106-112.

Borgland SL (2001) Acute opioid receptor desensitization and tolerance: is there a link? Clin Exp Pharmacol Physiol 28:147-154.

Brady LS, Herkenham M, Long JB, Rothman RB (1989) Chronic morphine increases mu-opiate receptor binding in rat brain: a quantitative autoradiographic study. Brain Res 477:382-386.

Bushell T, Endoh T, Simen AA, Ren D, Bindokas VP, Miller RJ (2002) Molecular components of tolerance to opiates in single hippocampal neurons. Mol Pharmacol 61:55-64.

Chu P, Murray S, Lissin D, von Zastrow M (1997) Delta and kappa opioid receptors are differentially regulated by dynamin-dependent endocytosis when activated by the same alkaloid agonist. J Biol Chem 272:27124-27130.

Connor M, Osborne PB, Christie MJ (2004) $\mu$-Opioid receptor desensitization: is morphine different? Br J Pharmacol 143:685-696.

Erdtmann-Vourliotis M, Mayer P, Ammon S, Riechert U, Hollt V (2001) Distribution of G-protein-coupled receptor kinase (GRK) isoforms 2, 3, 5 and 6 mRNA in the rat brain. Brain Res Mol Brain Res 95:129-137.

Evans CJ (2000) Agonist selective mu-opioid receptor trafficking in rat central nervous system. Mol Psychiatry 5:121-124.

Gurevich EV, Benovic JL, Gurevich VV (2002) Arrestin2 and arrestin3 are differentially expressed in the rat brain during postnatal development. Neuroscience 109:421-436.

Haberstock-Debic H, Wein M, Barrot M, Colago EE, Rahman Z, Neve R, Pickel VM, Nestler EJ, von Zastrow M, Svingos AL (2003) Morphine acutely regulates opioid receptor trafficking selectively in dendrites of nucleus accumbens neurons. J Neurosci 23:4324-4332.

Heimer L, Switzer RD, Van Hoesen GW (1982) Ventral striatum and ventral pallidum: components of the motor system? Trends Neurosci 5:83-87.

Kaufman DL, Keith Jr DE, Anton B, Tian J, Magendzo K, Newman D, Tran TH, Lee DS, Wen C, Xia YR (1995) Characterization of the murine mu opioid receptor gene. J Biol Chem 270:15877-15883.

Keith DE, Murray SR, Zaki PA, Chu PC, Lissin DV, Kang L, Evans CJ, von Zastrow M (1996) Morphine activates opioid receptors without causing their rapid internalization. J Biol Chem 271:19021-19024.

Keith DE, Anton B, Murray SR, Zaki PA, Chu PC, Lissin DV, Monteillet AV, Stewart PL, Evans CJ, von Zastrow M (1998) mu-Opioid receptor internalization: opiate drugs have differential effects on a conserved endocytic mechanism in vitro and in the mammalian brain. Mol Pharmacol 53:377-384.

Kieffer BL (1999) Opioids: first lessons from knockout mice. Trends Pharmacol Sci 20:19-26.

Kim KA, von Zastrow M (2003) Neurotrophin-regulated sorting of opioid receptors in the biosynthetic pathway of neurosecretory cells. J Neurosci 23:2075-2085.

Koch T, Schulz S, Schroder H, Wolf R, Raulf E, Hollt V (1998) Carboxylterminal splicing of the rat mu opioid receptor modulates agonist- 
mediated internalization and receptor resensitization. J Biol Chem 273:13652-13657.

Koch T, Schulz S, Pfeiffer M, Klutzny M, Schroder H, Kahl E, Hollt V (2001) $\mathrm{C}$-terminal splice variants of the mouse mu-opioid receptor differ in morphine-induced internalization and receptor resensitization. J Biol Chem 276:31408-31414.

Kovoor A, Celver JP, Wu A, Chavkin C (1998) Agonist induced homologous desensitization of mu-opioid receptors mediated by $\mathrm{G}$ proteincoupled receptor kinases is dependent on agonist efficacy. Mol Pharmacol 54:704-711.

Krupnick JG, Santini F, Gagnon AW, Keen JH, Benovic JL (1997) Modulation of the arrestin-clathrin interaction in cells. Characterization of betaarrestin dominant-negative mutants. J Biol Chem 272:32507-32512.

Lin F-T, Krueger KM, Kendall HE, Daaka Y, Fredericks ZL, Pitcher JA, Lefkowitz RJ (1997) Clathrin-mediated endocytosis of the $\beta$-adrenergic receptor is regulated by phosphorylation/dephosphorylation of $\beta$-arrestin1. J Biol Chem 49:31051-31057.

Maxfield FR, McGraw TE (2004) Endocytic recycling. Nat Rev Mol Cell Biol 2:121-132.

Menard L, Ferguson SS, Zhang J, Lin FT, Lefkowitz RJ, Caron MG, Barak LS (1997) Synergistic regulation of beta2-adrenergic receptor sequestration: intracellular complement of beta-adrenergic receptor kinase and betaarrestin determine kinetics of internalization. Mol Pharmacol 5:800-808.

Niwa H, Yamamura K, Miyazaki J (1991) Efficient selection for high-expression transfectants with a novel eukaryotic vector. Gene 108:193-199.

Qiu Y, Law PY, Loh HH (2003) Mu-opioid receptor desensitization: role of receptor phosphorylation, internalization, and representation. J Biol Chem 278:36733-36739.

Reddy PL, Veeranna, Matwyshyn GA, Thorat SN, Bhargava HN (1994) Effect of morphine tolerance and abstinence on the binding of $\left[{ }^{3} \mathrm{H}\right]$ naltrexone to discrete brain regions and spinal cord of the rat. Gen Pharmacol 25:355-361.

Santini F, Penn RB, Gagnon AW, Benovic JL, Keen JH (2000) Selective recruitment of arrestin-3 to clathrin coated pits upon stimulation of $\mathrm{G}$ protein-coupled receptors. J Cell Sci 113:2463-2470.

Schulz S, Mayer D, Pfeiffer M, Stumm R, Koch T, Hollt V (2004) Morphine induces terminal micro-opioid receptor desensitization by sustained phosphorylation of serine-375. EMBO J 23:3282-3290.
Shenoy SK, McDonald PH, Kohout TA, Lefkowitz RJ (2001) Regulation of receptor fate by ubiquitination of activated beta 2 -adrenergic receptor and beta-arrestin. Science 294:1307-1313.

Shiomi H, Kuraishi Y, Ueda H, Harada Y, Amano H, Takagi H (1981) Mechanism of kyotorphin-induced release of Met-enkephalin from guinea pig striatum and spinal cord. Brain Res 221:161-169.

Sternini C, Spann M, Anton B, Keith DJ, Bunnett NW, von Zastrow M, Evans C, Brecha NC (1996) Agonist-selective endocytosis of mu opioid receptor by neurons in vivo. Proc Natl Acad Sci USA 93:9241-9246.

Tao P-L, Law P-Y, Loh HH (1987) Decrease in delta and mu opioid receptor binding capacity in rat brain after chronic etorphine. J Pharmacol Exp Ther 240:809-816.

Terman GW, Jin W, Cheong YP, Lowe J, Caron MG, Lefkowitz RJ, Chavkin C (2004) G-protein receptor kinase 3 (GRK3) influences opioid analgesic tolerance but not opioid withdrawal. Br J Pharmacol 141:55-64.

Trafton JA, Abbadie C, Marek K, Basbaum AI (2000) Postsynaptic signaling via the $\mu$-opioid receptor: responses of dorsal horn neurons to exogenous opioids and noxious stimulation. J Neurosci 20:8578-8584.

Tsao PI, von Zastrow M (2000) Type-specific sorting of G protein-coupled receptors after endocytosis. J Biol Chem 275:11130-11140.

Ventimiglia R, Lindsay RM (1998) Rat striatal neurons in low-density, serum-free culture. In: Culturing nerve cells, Ed 2 (Banker G, Goslin K, eds), pp 370-393. Cambridge, MA: MIT.

Whistler JL, von Zastrow M (1998) Morphine-activated opioid receptors elude desensitization by beta-arrestin. Proc Natl Acad Sci USA 95:9914-9919.

Whistler JL, Chuang HH, Chu P, Jan LY, von Zastrow M (1999) Functional dissociation of mu opioid receptor signaling and endocytosis: implications for the biology of opiate tolerance and addiction. Neuron 23:737-746.

Yu Y, Zhang L, Yin X, Sun H, Uhl GR, Wang JB (1997) Mu opioid receptor phosphorylation, desensitization, and ligand efficacy. J Biol Chem 272:28869-28874.

Zhang J, Ferguson SS, Barak LS, Bodduluri SR, Laporte SA, Law PY, Caron MG (1998) Role for G protein-coupled receptor kinase in agonistspecific regulation of mu-opioid receptor responsiveness. Proc Natl Acad Sci USA 95:7157-7162. 